or not similar influences are exerted on the vaginal-cervical bacterial flora remains to be investigated.

Financial aid for this study was provided by the Medical Research Council (grant 19X-765) and the Expressen Foundation for Prenatal Research.

Requests for reprints should be addressed to Dr I Bollgren, Department of Paediatrics, Karolinska Hospital, S-10401 Stockholm, Sweden.

\section{References}

${ }^{1}$ Hood, M, Janney, A, and Dameron, G, American Fournal of Obstetrics and Gynecology, 1961, 82, 809.

2 Eickhoff, T C, et al, New England fournal of Medicine, 1964, 271, 1221.

${ }^{3}$ Bergqvist, G, et al, Scandinavian Fournal of Infectious Diseases, 1971, 3, 157.

${ }^{4}$ Franciosi, R A, Knostman, J D, and Zimmerman, R A, fournal of Pediatrics, 1973, 82, 707.

Baker, C J, and Barrett, F F, Fournal of Pediatrics, 1973, 83, 919.

${ }^{6}$ McCracken, G H, fournal of Pediatrics, 1973, 82, 703.

7 Wilson, H D, and Eichenwald, H F, Pediatric Clinics of North America, 1974, 21, 571 .

${ }^{8}$ Stamey, T A, et al, California Medicine, 1971, 115, 1.

${ }^{9}$ Bollgren, I, and Winberg, J, Acta Paediatrica Scandinavica, 1976, 65, 74.
${ }_{10}$ Bollgren, I, and Winberg, J, Acta Paediatrica Scandinavica, 1976, 65, 81. ${ }^{1}$ Hallmann, L, Bakteriologie und Serologie. Stuttgart, Georg Thieme Verlag, 1961.

12 Christie, R, Atkins, N E, and Munch-Petersen, E, Australian fournal of Experimental Biology and Medical Science, 1944, 22, 197.

${ }_{13}$ Lancefield, R C, Fournal of Experimental Medicine, 1933, 57, 571.

14 Facklam, R R, Applied Microbiology, 1973, 26, 138.

15 Nord, C-E, Lindberg, A A, and Dahlbäck, A, Medical Microbiology and Immunology, 1974, 159, 211.

16 Gästrin, B, Kallings, L O, and Marcetic, A, Acta Pathologica et Microbiologica Scandinavica, 1968, 74, 371.

17 Bergqvist, G, et al, Scandinavian fournal of Infectious Diseases, 1971, 3, 209.

18 Grüneberg, R N, Lancet, 1969, 2, 766.

19 Badri, M S, et al, Fournal of Infectious Diseases, 1977, 135, 308.

${ }^{20} \mathrm{Kexel}, \mathrm{G}$, and Beck, K J, Geburtshilfe und Frauenheilkunde, 1965, 25, 1078.

21 Jones, C P, and Martin, D S, American fournal of Obstetrics and Gynecology, 1938, 35, 98.

22 Baker, C J, et al, fournal of Infectious Diseases, 1977, 135, 392.

${ }^{23}$ Christensen, K K, et al, Scandinavian Fournal of Infectious Diseases, 1976, $8,75$.

${ }^{24}$ Wallin, J, and Forsgren, A, British Fournal of Venereal Diseases, 1975, 51, 401.

25 Catterall, R D, Lancet, 1966, 2, 830

26 Joshi, U M, et al, Contraception, 1971, 3, 327.

27 Chipperfield, E J, and Evans, B A, Infection and Immunity, 1975, 11, 215.

(Accepted 15 March 1978)

\title{
Prevention of secondary cases of meningococcal disease in household contacts by vaccination
}

\author{
B M GREENWOOD， M HASSAN-KING， H C WHITTLE
}

British Medical fournal, 1978, 1, 1317-1319

\section{Summary and conclusions}

Household contacts of patients with group A meningococcal infection were vaccinated with either meningococcal vaccine or tetanus toxoid. Five of the 523 subjects who received tetanus toxoid developed meningococcal meningitis and another four probably had meningococcal disease. Only one possible case of meningococcal infection occurred among 520 contacts vaccinated with meningococcal vaccine. Vaccination had no effect on nasopharyngeal carriage of meningococci.

Vaccination of household contacts of patients with group A meningococcal infections is an effective way of using limited supplies of meningococcal vaccine, though its value would be limited in an epidemic. Secondary cases of meningococcal infection often occur within a few days of the index case, and, although vaccine alone seemed to provide adequate prophylaxis in these Nigerian subjects, additional chemoprophylaxis may be needed to cover this critical period.

\section{Introduction}

Family contacts of patients with meningococcal meningitis or septicaemia have an increased chance of contracting the disease.

Department of Medicine, Ahmadu Bello University, Zaria, Nigeria B M GREENWOOD, FRCP, senior lecturer in medicine M HASSAN-KING, MSC, senior technologist

H C WHITTLE, MRCP, senior lecturer in medicine
A recent nationwide survey in the United States showed that the attack rate among household contacts of patients with the endemic form of the infection was approximately 3 per 1000 . In Los Angeles during 1963-6 the attack rate among household contacts of people with sporadic infection was about 10 per 1000. ${ }^{2}$ Higher secondary attack rates, however, ranging from 11 per 1000 to 59 per 1000 , have been recorded in the United States during epidemics. ${ }^{3-6}$ The secondary attack rate during an epidemic of group A meningococcal disease in Chile was 25 per $1000,{ }^{7}$ and during a more recent epidemic of predominantly group $\mathrm{C}$ infection in Brazil it was 16 per $1000 .{ }^{8}$ We have found no report on the incidence of secondary cases during the epidemics of meningococcal infection that often affect the savanna region of tropical Africa.

Because of their increased likelihood of contracting the in 'ection family contacts of patients with meningococcal disease are usually given some form of chemoprophylaxis. Sulphonamides have been widely and successfully used for this purpose bit they can no longer be relied on because of the emtrgence of sulphonamide-resistant meningococci. Minocycline and ::fampicin prevent carriage in household $\operatorname{contacts}^{6}$ but it has yet to be definitely established that they can prevent secondary cases of the disease. ${ }^{9}$ We therefore studied whether vaccination could be used as an alternative form of prophylaxis for close contacts of patients with meningococcal infection.

\section{Patients and methods}

During March-May 19771003 patients with meningococcal disease were admitted to Ahmadu Bello University Hospital, Zaria, Nigeria. In nearly all cases the causative organism was a group A sulphonamideresistant meningococcus.

Meningococcal infection was diagnosed when meningococci were cultured from blood or cerebrospinal fluid (CSF) or when meningococcal antigen " as detected in serum or cerebrospinal fluid by counter- 
current immunoelectrophoresis or by latex test. The diagnosis was also accepted in patients with a suggestive clinical picture whose initial serum sample contained group A meningococcal haemagglutinating antibody at a titre of $1 / 32$ or greater or in whom a rise in antibody titre of more than two doubling dilutions was observed between the acute phase and convalescent phase serum samples. A titre of $1 / 32$ was chosen, as we have shown in population surveys that only about $1 \%$ of the population have group A meningococcal haemagglutinating antibody at a titre of $1 / 32$ or higher.

Each evening throughout the epidemic the families of all patients admitted to hospital that day with meningococcal disease were interviewed and asked whether anyone in their compound had recently been ill. In most cases we were able to confirm histories suggestive of a previous case of meningitis by referring to our records of hospital admissions. In a few cases, however, a person with a suspicious history had not been brought to hospital or had died at home. Diagnosis was accepted in these cases only if a clear history of meningitis was obtained. At this interview families were selected for vaccination if their compound was readily accessible and if they had a co-operative compound head. The type of compound that we visited most often contained an extended family with a household head, one to four wives and their children, and a few other relatives and lodgers. In small compounds, everyone was included in the study but in large compounds only members of the immediate family group were investigated. The average number of subjects studied per compound was 17 . We also studied seven Koranic schools. Pupils at these traditional schools live in the school, often under very crowded conditions with many sleeping in a single room. The average population of the Koranic schools was also 17.

On the morning after interview selected compounds were visited, their members counted, and nasopharyngeal swabs collected. Alternate compounds were vaccinated with group $\mathrm{A}$ and group $\mathrm{C}$ meningococcal vaccine (Merieux), of which only 500 doses were available, or tetanus toxoid. Tetanus is relatively common in Zaria and vaccination infrequent. Ninety-five per cent of those counted were swabbed and vaccinated but in some compounds we were not told about people who were away on the day of our visit. Compound heads were issued with a special identity card and asked to bring any member of their compound who became ill to hospital immediately.

Two weeks after vaccination a second nasopharyngeal swab was collected, an $85 \%$ completion rate being obtained. All compounds were visited a third time at the end of the epidemic to check whether any illness had occurred in the compound since the time of vaccination.

Laboratory methods-Nasopharyngeal swabs were collected using charcoal-coated swabs. These were plated directly on to sheep blood agar plates containing vancomycin $2 \mathrm{mg} / \mathrm{l}$ and polymyxin $3 \mathrm{mg} / \mathrm{l}$. Likely colonies were subcultured on to Mueller-Hinton medium and meningococci identified by Gram stain, oxidase test, ONPG, and

TABLE I-Time interval between onset of illness in index and secondary cases of meningococcal disease

\begin{tabular}{lr|r|r|r|r|r}
\hline \multicolumn{2}{r|}{ Time (days) : } & $\leqslant 4$ & $5-14$ & $15-27$ & $\geqslant 28$ & Total \\
\hline Family contacts .. & $\ldots$ & 36 & 31 & 8 & 4 & 79 \\
Koranic school contacts & $\ldots$ & 4 & 7 & 2 & 4 & 17 \\
State school contacts &. & 8 & 3 & 1 & 0 & 12 \\
\hline & Total & 48 & 41 & 11 & 8 & 108 \\
\hline
\end{tabular}

sugar reactions. Serotyping was performed by agglutination in Perspex trays using rabbit antisera. Meningococcal antibodies were measured by haemagglutination using vaccine-coated human red cells.

\section{Results}

Incidence of secondary cases-The families of 905 patients with $\hookrightarrow$ meningococcal disease were interviewed. In 101 cases a history of a recent illness, which was probably meningococcal disease, in a $\frac{\overrightarrow{7}}{0}$ member of the same household or Koranic school as the patient was obtained. Given a compound size of 17 , the figure obtained in the prospective part of the study, this indicates a secondary attack rate of $\frac{0}{7}$ approximately 7 per 1000 . In a further 12 cases a history of a previous $\mathbb{Q}$ case in the same State primary or secondary school as the patient was obtained. Three members of the hospital staff (rough number 700) developed meningitis-a staff nurse, a maid working in the children's $\vec{O}$ emergency room, and a student technologist. Table I shows the time interval between the onset of illness in index and in secondary cases. In five cases both patients became ill on the same day.

Effect of vaccination on incidence of secondary cases-Seven of the 523 household contacts of patients with group A meningococcal infection who were given tetanus vaccine developed pyogenic menin- $\dot{\sigma}$ gitis, proved by lumbar puncture, during the epidemic. In five cases $\vec{N}$ the meningitis was shown to be due to a group A meningococcal infection, and meningococcal infection was probable in the remaining $\vec{\omega}$ two patients (table II). In addition two other household contacts $\vec{v}$ developed a septicaemic illness which was associated with serological $ᄋ$ evidence of group A meningococcal infection. None of the 520 household contacts given meningococcal vaccine developed meningitis.

TABLE III-Effects of meningococcal and tetanus vaccines on incidence of secondary cases in household contacts of patients with meningococcal disease

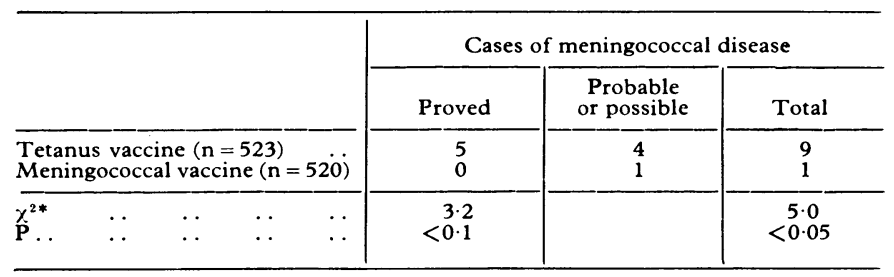

${ }^{*} \chi^{2}$ with Yates's correction.

A 10-year-old girl developed an acute febrile illness, which might have been meningococcaemia, 10 days after vaccination but she died on the way to hospital and was not seen by a doctor. Two cases of proved group A meningococcal meningitis (not shown in the table) occurred in members of compounds where people had received meningococcal vaccine. Both of these patients had been away on the day that their compound was visited and they had not been vaccinated. Early vaccination with meningococcal vaccine thus reduced the incidence of secondary meningococcal infection in household contacts (table III).

Meningococcal carriage in household contacts-The overall nasopharyngeal carriage rate of group A meningococci in 1016 household 
contacts of patients with group A meningococcal disease was only $3.7 \%$. A higher carriage rate of $7.7 \%$ was, however, found among 220 members of the immediate family group (parents, children, or siblings). The carriage rate among those who received meningococcal vaccine was $4.3 \%$ and among those who received tetanus toxoid $3.1 \%$.

Effect of vaccination on meningococcal carriage-The effects of tetanus toxoid and meningococcal vaccine on the nasopharyngeal carriage of group A and group $\mathrm{C}$ meningococci in household contacts are shown in table IV. Meningococcal vaccination did not lower the carriage rate.

TABLE IV-Number of family contacts carrying group $A$ or group $C$ meningococci at time of vaccination with group $A$ plus group $C$ meningococcal vaccine or tetanus toxoid and at two weeks after vaccination

\begin{tabular}{|c|c|c|c|c|}
\hline & \multicolumn{2}{|c|}{ Group A } & \multicolumn{2}{|c|}{ Group C } \\
\hline & lst swab & 2nd swab & 1st swab & 2nd swab \\
\hline $\begin{array}{l}\text { Meningococcal vaccine }(n=431) \\
\text { Tetanus vaccine }(n=450)\end{array}$ & $\begin{array}{l}19 \\
15\end{array}$ & $\begin{array}{l}29 \\
15\end{array}$ & $\begin{array}{l}3 \\
4\end{array}$ & $\begin{array}{l}6 \\
6\end{array}$ \\
\hline
\end{tabular}

\section{Discussion}

During an epidemic of group A meningococcal infection in an area within the African meningitis belt ${ }^{10}$ we observed a secondary attack rate of 18 per 1000 among household contacts of patients with the disease who were given tetanus toxoid and carefully followed throughout the epidemic. Less precise data obtained by interviewing families of patients suggested a secondary attack rate of about 7 per 1000 ; this figure is probably an underestimate because of the difficulty of establishing a diagnosis retrospectively. These secondary attack rates are comparable with those recorded in other parts of the world during epidemics of group A meningococcal infection. ${ }^{3-7}$ The risk of infection was greatest among close family contacts, especially among siblings of the index case. As found in Brazil,"1 little spread occurred in day schools but several secondary cases occurred among pupils in Koranic schools, where contact between the boarders is often as close as in small family groups.

Meningococcal vaccine successfully prevented secondary infections in household contacts when given on the day after admission of the index case to hospital. Vaccination of household contacts is an effective way of using this vaccine when only limited amounts are available, but it cannot be expected to control an epidemic, for only about $10^{\circ}{ }^{\prime}$ of cases occur in the families of affected patients. Our results suggest that all household contacts of patients with group $\mathrm{A}$ or group $\mathrm{C}$ meningococcal infection should be vaccinated as soon as possible. It is less certain whether other contacts need protection. Contacts at day schools are probably not at risk ${ }^{11}$ and do not require prophylaxis. Non-family contacts living in close contact with a patient-for example, in a lodging house ${ }^{12}$ or, as in our study, Koranic schools-should probably be vaccinated. The risk of hospital infection is thought to be low but three members of the hospital staff contracted the infection during this epidemic and another hospital infection has recently been reported in Finland. ${ }^{12}$ Vaccination of medical, nursing, and laboratory staff likely to be in frequent contact with patients with meningococcal disease or with infected samples is therefore probably advisable, especially in tropical Africa, where adults are affected more often than in Europe and America.

Many secondary cases of meningococcal infection occur within a few days of the onset of illness in the index case. It has therefore been suggested that vaccination of household contacts would be unlikely to be an effective form of prophylaxis. ${ }^{13}$ This did not prove to be the case in this study. Low titres of serum antibody to group $\mathbf{A}$ meningococci, perhaps acquired as a result of infection with cross-reacting organisms, are found in most healthy subjects living in Zaria and the surrounding areas. In these circumstances vaccination may induce a rapid secondary immune response which, within two or three days, results in the production of enough antibody to prevent systemic invasion by meningococci. Nevertheless, the absence of secondary cases during the first few days after vaccination in this study may have been a chance phenomenon and some additional prophylaxis may be needed to cover this critical period. This may be especially important in Europe and America, where secondary cases occur more often in young children than in Nigeria, for young children are relatively poor responders to vaccination. ${ }^{1415}$ Sulphonamides can no longer be relied on, particularly in Africa, as most meningococci are now resistant ( $M$ Hassan-King, unpublished). Rifampicin is probably the best choice for an additional chemotherapeutic agent but its extensive use is likely to lead to widespread resistance and the drug is expensive. Penicillin is a possible alternative for developing countries with limited budgets but it needs to be given in a full therapeutic dose to be effective (M Hassan-King). ${ }^{16}$

Vaccination with group A plus group $C$ vaccine had no effect on the nasopharyngeal carriage of group $\mathrm{A}$ or group $\mathrm{C}$ meningococci in household contacts, again suggesting that vaccination may have to be combined with some chemoprophylaxis. Our results differ from those found in military camps, where meningococcal vaccines have been moderately effective in reducing carriage rates. ${ }^{1718}$ In these camps, however, a very high proportion of recruits become carriers, while carriage is much less common among contacts of civilian cases. Perhaps household contacts who become carriers are a special group who have difficulty in eliminating meningococci after either natural infection or vaccination.

We thank the Institute Merieux for providing the meningococcal vaccine and Dr J D Abbott of the Public Health Laboratory, Withington Hospital, Manchester, for the gift of typing antisera and for his general help and encouragement. We also thank our clinical colleagues who allowed us to study patients admitted under their care. This study would not have been possible without the help provided by $\mathrm{Mr} \mathrm{H}$ Ndahi and Mr I Hamman. BMG and HCW are supported by the United Kingdom Medical Research Council.

\section{References}

${ }^{1}$ Meningococcal Disease Surveillance Group, fournal of the American Medical Association, 1976, 235, 261.

${ }^{2}$ Leedom, J M, et al, Antimicrobial Agents and Chemotherapy-1966, 1967, p 281.

${ }^{3}$ French, M R, American fournal of Public Health, 1931, 21, 130.

4 Pickett, W H, American fournal of Public Health, 1931, 21, 139.

${ }^{5}$ Lee, W W, fournal of Preventive Medicine, 1931, 5, 203.

6 Kaiser, A B, et al, fournal of Infectious Diseases, 1974, 130, 217.

${ }^{7}$ Pizzi, M, American fournal of Public Health, 1944, 34, 231.

${ }^{8}$ Munford, R S, et al, Lancet, 1974, 1, 1275.

${ }^{9}$ Meningococcal Disease Surveillance Group, fournal of Infectious Diseases, 1976, 134, 201.

${ }^{10}$ Lapeyssonnie, L, Bulletin of the World Health Organisation, 1963, 28, suppl.

11 Jacobson, J A, et al, American fournal of Epidemiology, 1976, 104, 552.

12 Salmi, I, et al, Scandinavian fournal of Infectious Diseases, 1976, 8, 249.

13 Artenstein, M S, fournal of the American Medical Association, 1975, 231, 1035.

${ }^{14}$ Goldschneider, I, Lepow, M L, and Gotschlich, E C, fournal of Infectious Diseases, 1972, 125, 509

${ }^{15}$ Monto, A S, Brandt, B L, and Artenstein, M S, fournal of Infectious Diseases, 1973, 127, 394.

${ }^{16}$ Artenstein, M S, Lamson, T H, and Evans, J R, Military Medicine, 1967, 132, 1009.

17 Gotschlich, E C, Goldschneider, I, and Artenstein, M S, fournal of Experimental Medicine, 1969, 129, 1385.

18 Artenstein, M S, et al, New England fournal of Medicine, 1970, 282, 417.

(Accepted 15 March 1978) 